\title{
The associated risk factors for the diagnosis of asthma in the preschool age children followed up with chronic non-specific cough
}

\author{
Fatih Kaplan ${ }^{1}$ and Erdem Topal ${ }^{1}$ \\ ${ }^{1}$ Inonu University
}

February 18, 2022

\begin{abstract}
Background: Chronic nonspecific cough is one of the important reasons for doctor visits in childhood. The aim of this study is to determine the incidence of asthma diagnosis in preschool children followed up with the diagnosis of chronic non-specific cough and the factors associated with the diagnosis of asthma. Methods: The files of preschool children who were followed up with the diagnosis of chronic non-specific cough were retrospectively reviewed. Information such as demographic data of the patients, treatments given for chronic non-specific cough, cough scores during the follow-up etc. was recorded from the medical files. The patients who were diagnosed with asthma during the follow-up were included in the Group 1 , and the other patients were included in the Group 2. Results: A total of 226 patients were enrolled in the study. Of the patients with the mean age of 4 years (min:1-max:6), 102 (45.1\%) were female. The median follow-up time of the patients was 30 months (min:30-max:34). No significant difference was found between the two groups in terms of age, sex and follow-up time. During the follow-up, 137 patients $(60.6 \%)$ were diagnosed with asthma. In our study, the asthma-associated factors in follow up were determined to be parental asthma, sibling asthma, aeroallergen sensitivity, elevated total serum IgE, eosinophilia and low-income level. Conclusions: More than half of preschool age children with chronic nonspecific cough receive the diagnosis of asthma. Therefore, patients with risk factors such as parental asthma, sibling asthma, aeroallergen sensitivity, elevated serum total IgE, eosinophilia and low-income level should be followed up for asthma.
\end{abstract}

\section{Hosted file}

main document.docx available at https://authorea.com/users/461120/articles/556889-theassociated-risk-factors-for-the-diagnosis-of-asthma-in-the-preschool-age-childrenfollowed-up-with-chronic-non-specific-cough

\section{Hosted file}

figures.pdf available at https://authorea.com/users/461120/articles/556889-the-associatedrisk-factors-for-the-diagnosis-of-asthma-in-the-preschool-age-children-followed-up-withchronic-non-specific-cough 